\title{
Mutations in the Cysteine-Rich Region of the RET Proto-Oncogene in Patients Diagnosed as Having Sporadic Medullary Thyroid Carcinoma
}

\author{
TAKEHIKO KIMURA, KATSUHIKO YOSHIMOTO*, \\ YUTAKA YOKOGOSHI, AND SHIRO SAITO \\ The First Department of Internal Medicine and *Otsuka Department of \\ Clinical and Molecular Nutrition, School of Medicine, The University of \\ Tokushima, Tokushima 770, Japan
}

\begin{abstract}
Medullary thyroid carcinoma (MTC) and pheochromocytoma appear in either a sporadic or a hereditary form as components of multiple endocrine neoplasia (MEN). Many germline mutations of the RET proto-oncogene have been reported in patients with MEN 2A and 2B, and familial MTC (FMTC). To elucidate the etiological roles in tumorigenesis of sporadic MTCs and pheochromocytomas, mutations in the cysteine-rich region of the RET proto-oncogene were analyzed by using polymerase chain reaction-single strand conformation polymorphism (PCR-SSCP) analysis. Exons 10 and 11 were studied in genomic DNAs from 3 clinically apparent sporadic MTCs, MTCs and pheochromocytomas from 2 patients with MEN 2A, 1 with FMTC, 4 with MEN 2B, 3 with neurofibromatosis type 1 (NF1), 12 sporadic pheochromocytomas and an MTC cell line, TT. All tumors from two patients with MEN 2A and one patient with FMTC had mutations at codon 618 and 634 as well as their leukocytes, reflecting their germline mutations. In this region, no mutations were detected in any tumors from patients with MEN 2B and NF1, and sporadic pheochromocytomas. But mutations were detected and identified in 3 clinically apparent sporadic MTCs and TT cells. A 6 base pair (bp) deletion causing the loss of a cysteine residue at codon 634 and a mutation causing substitution from cysteine to tyrosine at codon 634 were detected in 2 sporadic MTCs as somatic events. In a female patient diagnosed as having sporadic MTC, a mutation at codon 618 was detected not only in tumor tissues, but also in her leukocytes, suggesting a germline mutation of the RET proto-oncogene. In TT cells a heterozygous mutation at codon 634 was detected. These results suggest that RET mutations within a cysteine-rich region may also play an important role in the tumorigenesis of sporadic MTCs, and mutations of RET proto-oncogene should be screened in clinically sporadic cases to exclude hereditary MTCs.
\end{abstract}

Key words: RET proto-oncogene, Mutation, Sporadic MTC, MEN 2A, Genetic diagnosis

(Endocrine Journal 42: 517-525, 1995)

MTC, a tumor arising from the calcitonin-secreting parafollicular C-cells, comprises $5-10 \%$ of all malignancies arising from the thyroid gland [1]. This tumor appears either as a sporadic nonhereditary lesion or as a component of three familial

Received: October 8, 1994

Accepted: April 3, 1995

Correspondence to: Dr. Takehiko KIMURA, The First Department of Internal Medicine, School of Medicine, The University of Tokushima, 3-18-15, Kuramoto-cho, Tokushima 770, Japan syndromes, MEN 2A, MEN 2B and FMTC, which are inherited as an autosomal dominant trait. MEN $2 \mathrm{~A}$ is variably associated with pheochromocytoma and primary hyperparathyroidism. MEN 2B is associated with pheochromocytoma, marfanoid habitus, mucosal neuromas, and ganglioneuromatosis. FMTC is not associated with other endocrinopathies. Sporadic MTC, a tumor of moderate to marked aggressiveness, occurs during the fifth or sixth decade of life as a solitary unilateral thyroid mass without coexisting microscopic C-cell 
hyperplasia, associated endocrinopathies, or a familial history of MTC.

The loci of the three syndromes, MEN 2A, FMTC and MEN 2B, link to the chromosome 10q11.2 region, where the RET proto-oncogene has also been mapped [2,3]. Germline mutations of the RET proto-oncogene have been described in patients affected with MEN 2A, FMTC or MEN 2B [4-10]. The nonconservative substitution of the 5 cysteine residues located in the extracellular domain adjacent to the transmembrane domain of the RET protein has been detected in patients with MEN 2A and FMTC [4-6]. In patients with MEN 2B, a mutation at codon 918 causing the substitution of a threonine for a methionine in exon 16 of the tyrosine kinase domain of the RET protein has been detected at the germline level [8-10].

There are few data on the pathogenesis of sporadic MTC. Increased expression of the RET proto-oncogene has been found in MTCs of both familial and sporadic types as pheochromocytomas $[11,12]$. In this study, we screened mutations of the RET proto-oncogene in tumors and leukocyte DNA from patients with MEN 2A, MEN 2B, FMTC, NF1, sporadic pheochromocytoma and MTC, and a TT cell line by the PCR-SSCP method. We identified germline mutations in 2 MEN 2A and 1 FMTC patients as previously reported [4-6]. Interestingly we demonstrated nonconservative mutations in the cysteine-rich extracellular region adjacent to the transmembrane domain of the RET proto-oncogene in 3 MTCs diagnosed as sporadic MTCs and TT cells.

\section{Patients}

Patient 1 was a 94-year-old man who underwent gastrectomy because of a gastric ulcer at the age of 75. He was referred to Takamatsu Municipal Hospital for abdominal pain at the age of 92 . The physical examination was unremarkable. Because the serum level of carcinoembryonic antigen (CEA) was increased $(1,230 \mathrm{ng} / \mathrm{ml}$; normal, $<5 \mathrm{ng} / \mathrm{ml})$, the presence of colon cancer was suspected, but fiberoptic colonoscopy revealed no evidence of colon cancer. A computed tomographic (CT) scan revealed a mediastinal tumor adjacent to the right wall of the trachea, and thyroid ultrasonography revealed a space occupying a region in the right lobe. The basal serum calcitonin level was 5,981 $\mathrm{pg} / \mathrm{ml}$ (normal, $<100 \mathrm{pg} / \mathrm{ml}$ ). These findings established the diagnosis of MTC. He had no family history of MTC or pheochromocytoma. He elected not to undergo surgery, and he remained well until the appearance of a subdural hemorrhage. He died of respiratory failure from acute bronchopneumonia at the age of 94 . An autopsy revealed that the tumor was well demarcated, and its size was $5 \times 4.3 \times 3.5 \mathrm{~cm}$. The tumor consisted of spindle-shaped cells with eosinophilic cytoplasm. Amyloid was demonstrated among the fibrous stroma. Immunohistochemical staining for calcitonin and CEA revealed abundant signals in the cytoplasm of the neoplastic C-cells within the tumor mass. Calcitonin staining of the thyroid tissue outside the carcinoma revealed no other foci of MTC or C-cell hyperplasia in either lobe. No regional lymph nodes or distant metastases were detected. No pathologic abnormalities of the adrenal, parathyroid and pituitary glands were evident.

Patient 2 was a 48-year-old woman. On a regular physical examination, a thyroid nodule was found and she was referred to Takamatsu Municipal Hospital for further evaluation. Her history was unremarkable except for acute appendicitis at the age of 33. There was no family history of MTC or pheochromocytoma. Her serum CEA level was increased $(90 \mathrm{ng} / \mathrm{ml}$ ). Thyroid ultrasonography and CT scan showed a solitary mass in the left lobe, and scanning with radioactive iodine showed a cold nodule in the left lobe. She underwent left thyroid lobectomy. Histological diagnosis was MTC $(3 \times 1.5 \times 1.2 \mathrm{~cm})$ with regional lymph node metastases. The tumor was immunohistochemically positive for calcitonin and CEA, and there was marked interstitial deposition of amyloid. She was diagnosed as having sporadic MTC. Subsequently, she received radiation therapy to the neck. She has had no signs of recurrence for the past 7 years, and no clinical symptoms or other data suggest the presence of pheochromocytoma.

Patient 3 was a 36-year-old woman, whose thyroid tumor was first revealed by a physical examination. There was no family history of MTC or pheochromocytoma, and her two sisters and three children were healthy. At admission to Tokushima Municipal Hospital, her serum levels of calcitonin and CEA were $1,854 \mathrm{pg} / \mathrm{ml}$ and 96.3 $\mathrm{ng} / \mathrm{ml}$, respectively. Since a CT scan and ultrasonography revealed one tumor $(2.5 \times 1.8 \mathrm{~cm}$ in size) on the left lobe of the thyroid, subtotal thy- 
roidectomy was performed. A histological examination revealed that the tumor was MTC with regional lymph node metastases, and the noncancerous region of the thyroid showed findings of chronic thyroiditis but no apparent C-cell hyperplasia. There were no clinical or laboratory findings consistent with pheochromocytoma. She was diagnosed as having sporadic MTC. She has remained in good health without recurrence for 4 years since the operation.

\section{Materials and Methods}

\section{DNA preparation}

Tissues were obtained at surgery or autopsy, and a diagnosis of MTC was confirmed by histological examinations of the tumors. DNA was isolated from the tissues, leukocytes, and paraffin-embedded tissues, as described [13, 14]. DNAs were extracted from 3 clinically apparent sporadic MTCs, MTCs and pheochromocytomas from 2 patients with MEN 2A, MTC from 1 patient with FMTC, MTCs and pheochromocytomas from 4 patients with MEN 2B, pheochromocytomas from 3 patients with NF1, and 12 sporadic pheochromocytomas (Table 1). A human medullary thyroid carcinoma cell line, TT (CRL 1803) was obtained from ATCC.

\section{PCR-SSCP}

PCR amplification was performed by using the oligonucleotide primers described by Donis-Keller et al. [5]: 5'-GCGCCCCAGGAGGCTGAGTG-3' and 5'-CGTGGTGGTCCCGGCCGCC-3' for exon 10; 5'-CCTCTGCGGTGCCAAGCCTC-3' and 5'CACCGGAAGAGGAGTAGCTG-3' for exon 11 .

Table 1 Clinical features of patients and results of SSCP and sequencing analysis

\begin{tabular}{|c|c|c|c|c|c|c|c|}
\hline $\begin{array}{l}\text { Patient } \\
\text { No. }\end{array}$ & Age & Sex & Tumor & Diagnosis & SSCP variant & $\begin{array}{l}\text { Type of mutation } \\
\text { (codon) }\end{array}$ & $\begin{array}{l}\text { Germline } \\
\text { mutation }\end{array}$ \\
\hline 1. & 94 & M & MTC & sporadic & + & $\begin{array}{l}\text { GAGCTGTGC } \\
(632-634) \rightarrow \text { GGC }\end{array}$ & - \\
\hline 2. & 48 & $\mathrm{~F}$ & MTC & sporadic & + & TGC $(634) \rightarrow$ TAC & - \\
\hline 3. & 36 & $\mathrm{~F}$ & MTC & sporadic & + & TGC $(618) \rightarrow$ TCC & + \\
\hline 4. & 41 & $\mathrm{~F}$ & pheochromocytoma & sporadic & - & & \\
\hline 5. & 60 & $\mathrm{M}$ & pheochromocytoma & sporadic & - & & \\
\hline 6. & 50 & $\mathrm{M}$ & pheochromocytoma & sporadic & - & & \\
\hline 7. & 44 & $\mathrm{~F}$ & pheochromocytoma & sporadic & - & & \\
\hline 8. & 47 & $\mathrm{~F}$ & pheochromocytoma & sporadic & - & & \\
\hline 9. & 50 & $\mathrm{~F}$ & pheochromocytoma & sporadic & - & & \\
\hline 10. & 53 & $\mathrm{~F}$ & pheochromocytoma & sporadic & - & & \\
\hline 11. & 48 & M & pheochromocytoma & sporadic & - & & \\
\hline 12. & 69 & $\mathrm{~F}$ & pheochromocytoma & sporadic & - & & \\
\hline 13. & 70 & $\mathrm{~F}$ & pheochromocytoma & sporadic & - & & \\
\hline 14. & 64 & $\mathrm{~F}$ & pheochromocytoma & sporadic & - & & \\
\hline 15. & 42 & $\mathrm{~F}$ & pheochromocytoma & sporadic & - & & \\
\hline 16. & 46 & $\mathrm{~F}$ & $\begin{array}{l}\text { MTC } \\
\text { pheochromocytoma }\end{array}$ & MEN 2A & $\begin{array}{l}+ \\
+\end{array}$ & TGC $(618) \rightarrow$ TAC & + \\
\hline 17. & 42 & $\mathrm{~F}$ & MTC & MEN 2A & + & TGC $(634) \rightarrow$ TAC & + \\
\hline 18. & 60 & M & MTC & FMTC & + & TGC $(618) \rightarrow$ CGC & + \\
\hline 19. & 7 & $\mathrm{~F}$ & MTC & MEN 2B & - & & \\
\hline 20. & 18 & M & MTC & MEN 2B & - & & \\
\hline 21. & 28 & $\mathrm{~F}$ & $\begin{array}{l}\text { MTC } \\
\text { pheochromocytoma }\end{array}$ & MEN 2B & $\begin{array}{l}- \\
-\end{array}$ & & \\
\hline 22. & 10 & $\mathrm{~F}$ & MTC & MEN 2B & - & & \\
\hline 23. & 19 & $\mathrm{~F}$ & pheochromocytoma & NF1 & - & & \\
\hline 24. & 34 & $\mathrm{M}$ & pheochromocytoma & NF1 & - & & \\
\hline 25. & 44 & $\mathrm{~F}$ & pheochromocytoma & NF1 & - & & \\
\hline 26. & & & TT (MTC cell line) & sporadic & + & TGC (634) $\rightarrow$ TGG & $?$ \\
\hline
\end{tabular}


Amplified DNA fragments were all of the size expected (exon 10,187 bp; exon 11,234 bp). PCR proceeded in a Program Temp Control System PC700 (ASTEC, Fukuoka, Japan) with 50 ng of genomic DNA in a total volume of $5 \mu l$ containing $1.5 \mu \mathrm{Ci}$ of $\left[\alpha-{ }^{32} \mathrm{P}\right] \mathrm{dCTP}(3,000 \mathrm{Ci} / \mathrm{mmol} ; 10 \mathrm{mCi} /$ $\mathrm{ml})$. Thirty-five cycles consisted of $30 \mathrm{sec}$ at $94^{\circ} \mathrm{C}$ for denaturation, $30 \mathrm{sec}$ at $68^{\circ} \mathrm{C}$ for exon 10 , or at $65^{\circ} \mathrm{C}$ for exon 11 for annealing, and $1 \mathrm{~min}$ at $72^{\circ} \mathrm{C}$ for extension. The reaction mixture $(5 \mu l)$ was heated with $95 \mu l$ of dye ( $95 \%$ formamide $/ 20 \mathrm{mM}$ EDTA/0.05\% bromophenol blue/0.05\% xylene cyanol), then $1 \mu l$ of the mixture was applied to a $5 \%$ polyacrylamide gel containing $45 \mathrm{mM}$ Tris-borate (pH 8.3) and 4 mM EDTA. Glycerol (5\% or 10\%) was added when specified, as described [14]. Electrophoresis proceeded at $30 \mathrm{~W}$ for $4-6 \mathrm{~h}$ at room temperature or for $6-10 \mathrm{~h}$ at $4{ }^{\circ} \mathrm{C}$. The gel was dried and exposed to $\mathrm{X}$-ray film with intensifying screens at $-70{ }^{\circ} \mathrm{C}$ for 12 to $24 \mathrm{~h}$.

\section{Sequencing analysis}

Abnormal bands detected by PCR-SSCP were excised from the dried gel, placed in $100 \mu \mathrm{l}$ of distilled water, and incubated at $37^{\circ} \mathrm{C}$. An aliquot of the supernatant was then used as a template for the PCR reaction. PCR products were cloned into the $\mathrm{pCR}{ }^{\mathrm{TM}} \mathrm{II}$ vector with a TA Cloning kit (Invitrogen Co., San Diego, CA). Plasmid DNAs were sequenced with a Sequenase ${ }^{\mathrm{TM}}$ Version 2.0 DNA Sequencing Kit (Amersham, Buckinghamshire, UK) according to the manufacturer's instructions, then resolved on a $5 \%$ denaturing polyacrylamide gel. The accuracy of our sequencing data in cloned DNAs was confirmed by analyzing at least 10 independent clones.

\section{Reverse Transcription (RT)-PCR procedure}

Total RNA from TT cells was prepared by using acid guanidinium thiocyanate-phenol-chloroform extraction [15]. cDNA was made from $2 \mu \mathrm{g}$ of total RNA with M-MLV reverse transcriptase (Promega, Madison, WI) and random hexamers. The cDNA was then amplified by PCR in 30 cycles with 2 primers [5'-GGGGGATTAAAGCTGGCTAT-3' (exon 10) and 5'-TGGCTTGTGGGCAAACTTGT-3' (exon 11) (codon 600-667)]. The PCR conditions were as follows: 1 min denaturation at $94{ }^{\circ} \mathrm{C}, 1 \mathrm{~min}$ annealing at $60^{\circ} \mathrm{C}$ and $1 \mathrm{~min}$ extension at $72{ }^{\circ} \mathrm{C}$. DNA was electrophoresed on a $10 \%$ polyacrylamide gel, followed by ethidium bromide staining. The gels were photographed with an ultraviolet transilluminator.

\section{Results}

Screening of point mutations of the RET protooncogene by PCR-SSCP and sequencing

PCR-SSCP of exon 11 from genomic DNA of the sporadic MTC of patient 1, as shown in Fig. 1A, disclosed an extra band with an altered migration relative to those amplified from leukocytes of the same patient. Sequencing revealed a $6 \mathrm{bp}$ deletion including codons 632 to 634 in exon 11 (Fig. 2A). The deletion caused a loss of the cysteine residue at codon 634 from glutamine (codon 632)-leucine (codon 633)-cysteine (codon 634) (GAGCTGTGC, deleted 6 bp are underlined). PCR-SSCP of exon 11 from the MTC of patient 2, as shown in Fig. 1B, disclosed an extra band relative to those amplified from her leukocytes. As shown in Fig. 2B, codon 634 of TGC for cysteine was mutated to TAC for tyrosine by a $G$ to $A$ transition. The mutation of patient 1 destroyed a $A l u \mathrm{I}$ restriction site, and the mutation of patient 2 created a new $R s a$ I restriction site, and restriction analyses of PCR products also confirmed the results (data not shown). PCRSSCP of exon 10 from the MTC and the leukocytes of patient 3 revealed common extra bands relative to those amplified from leukocytes from a healthy subject (Fig. 1C). As shown in Fig. 2C, codon 618 of TGC for cysteine was mutated to TCC for serine by a $\mathrm{G}$ to $\mathrm{C}$ transversion in both MTC and leukocytes of this patient.

In these three MTCs, the other alleles of exon 11 (patients 1 and 2) or exon 10 (patient 3) of the RET proto-oncogene had normal sequences, and no detectable variations in exon 10 (patients 1 and 2) or exon 11 (patient 3) were revealed by PCR-SSCP. Direct sequencing of codon 918 of the RET protooncogene revealed normal sequences in these 3 MTCs.

We analyzed a panel of genomic DNAs of tumors from 2 patients with MEN 2A, 1 with FMTC, 4 with MEN 2B, 3 with NF1, and 12 sporadic pheochromocytomas for mutations in exons 10 and 11. PCR-SSCP and sequencing revealed germline mutations from cysteine (TGC) to tyrosine (TAC) at 


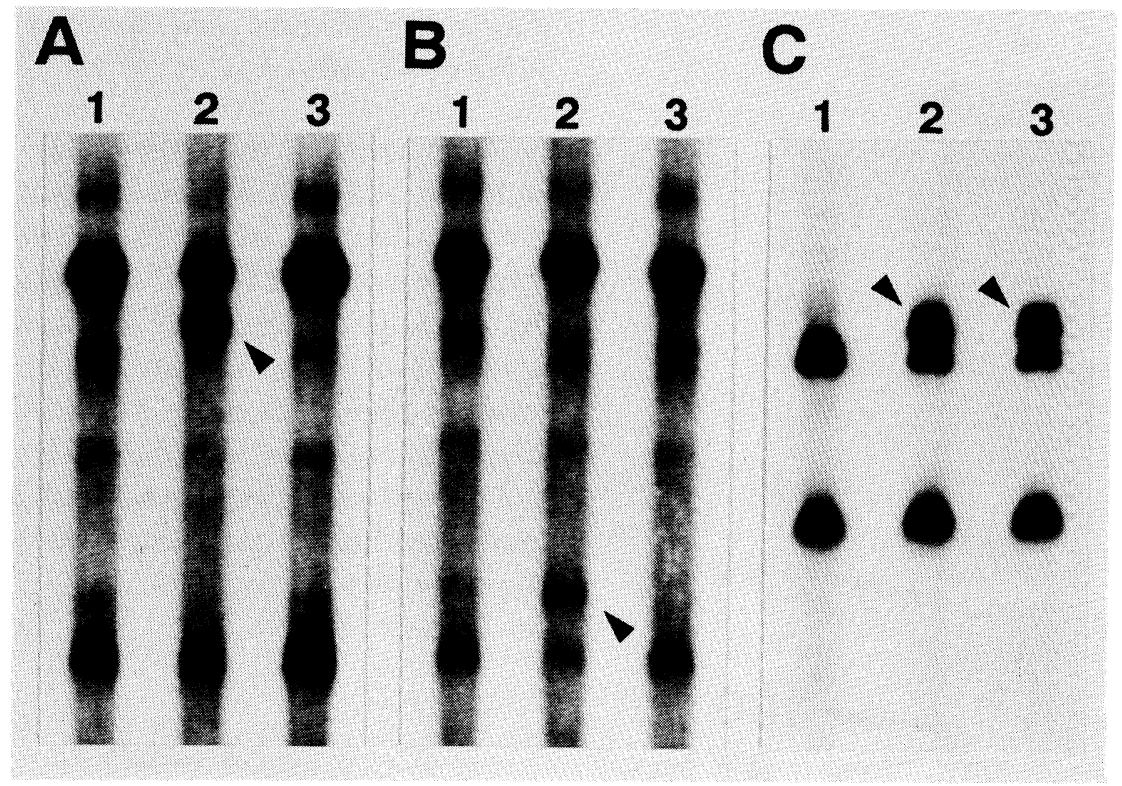

Fig. 1. PCR-SSCP of exons 11 (A and $\mathrm{B}$ ) and $10(\mathrm{C})$ of the RET proto-oncogene. Panels A, B and C show the PCR-SSCP profiles of patients 1, 2, and 3, respectively. A. Lane 1, leukocytes from a healthy subject; lane 2, MTC from patient 1 ; and lane 3 , leukocytes from patient 1 . B. Lane 1, leukocytes from a healthy subject; lane 2, MTC from patient 2; and lane 3, leukocytes from patient 2. C. Lane 1, leukocytes from a healthy subject; lane 2, MTC from patient 3; and lane 3, leukocytes from patient 3. Electrophoresis was performed in a $5 \%$ polyacrylamide gel without glycerol at room temperature. Arrow heads denote the bands with altered migration relative to controls.

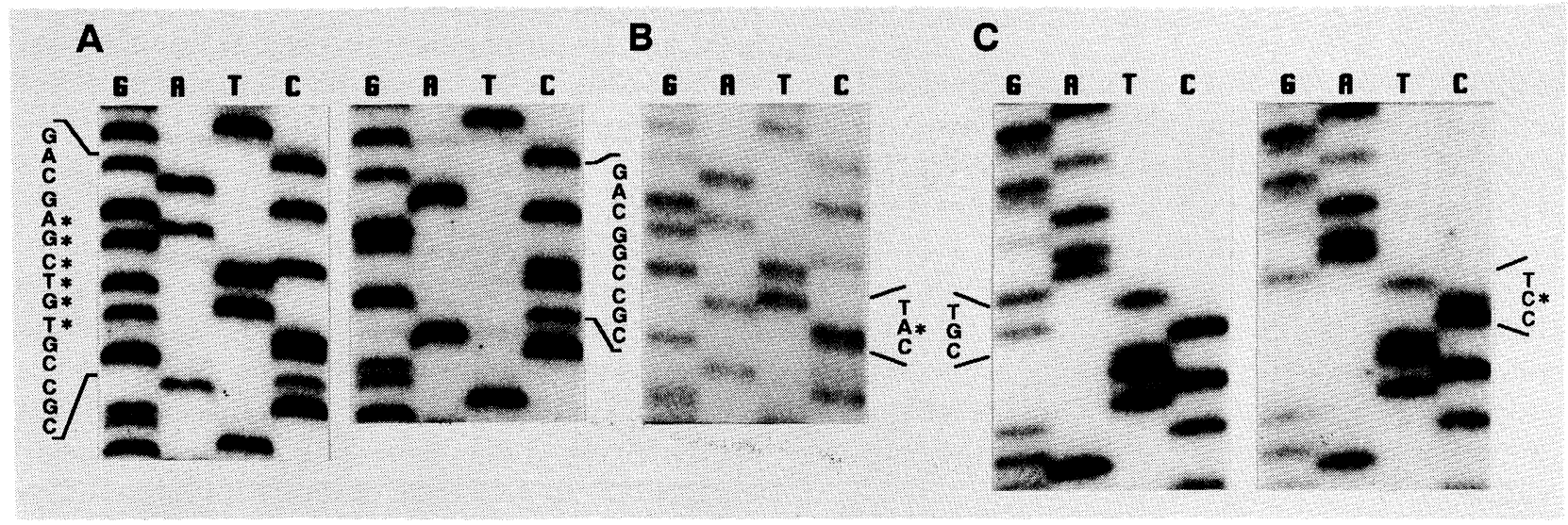

Fig. 2. Nucleotide sequence analysis of the RET proto-oncogene from genomic DNA. DNA fragments that showed a mobility shift on SSCP, and DNA from normal leukocytes were PCR-amplified. The PCR products were cloned into the $\mathrm{pCR}^{\mathrm{TM}} \mathrm{II}$ vector and sequenced. A. Sequence of the variant allele at exon 11 of the RET proto-oncogene from a MTC of patient 1. The left panel shows the normal sequence of codons 630-637. The right panel shows the 6 bp deletion. Deleted bases are indicated by asterisks in the left panel. B. Sequence of the variant allele at exon 11 of the RET protooncogene from MTC of patient 2. The panel shows the G to A transition at codon 634. The mutated base is indicated by an asterisk. C. Sequence of the variant allele at exon 10 of the RET proto-oncogene from an MTC of patient 3 . The left panel shows the normal sequence of codons 614-621. The right panel shows the $G$ to $C$ transversion at codon 618 . The mutated base is indicated by an asterisk. 


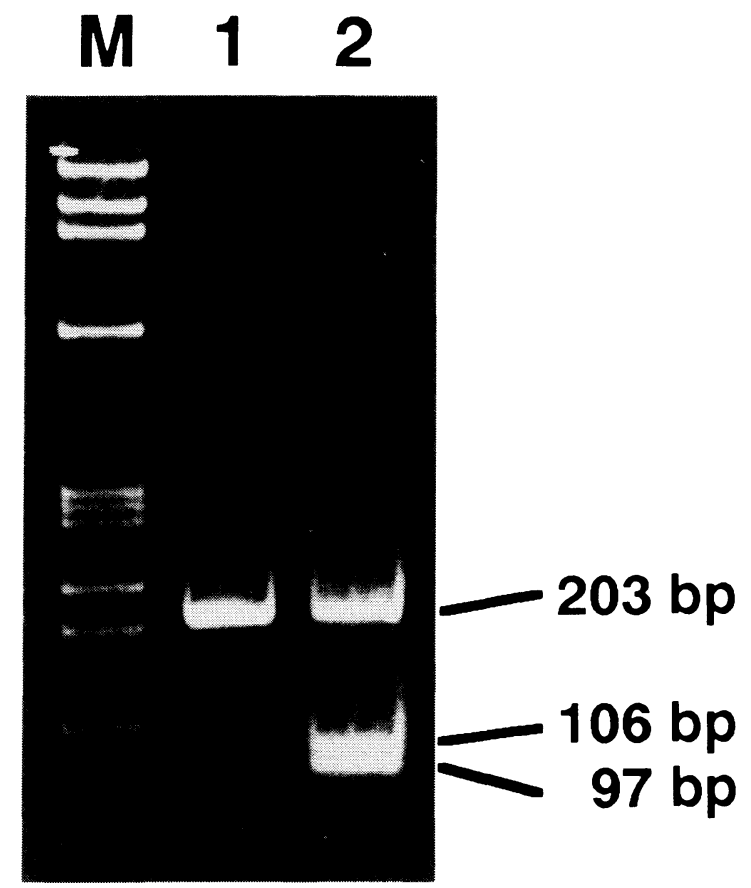

Fig. 3. HhaI restriction enzyme digestions of PCR fragments amplified cDNA from TT cells. A fragment including part of exons 10 and 11 was amplified by 2 primers described in Materials and Methods. M, øX174 HaeIII-digested DNA fragments used as molecular weight markers; lane 1, undigested fragment (203 bp); lane 2, HhaI digested fragments (203, 106 and $97 \mathrm{bps})$.

codon 618 and 634 in 2 patients with MEN 2A, and to arginine (CGC) at codon 618 in one patient with FMTC. The results are summarized in Table 1. These PCR reactions were repeated several times for each sample. In all cases PCR-SSCP and sequence analyses confirmed the results. No extra bands in PCR-SSCP of exons 10 and 11 were detected in tumors from patients with MEN 2B and sporadic pheochromocytomas. These results were also confirmed by directly sequencing the genomic DNAs.

In TT cells, we detected a heterozygous mutation at codon 634 (TGC for cysteine to TGG for tryptophan) of the RET proto-oncogene by PCRSSCP analysis and nucleotide sequencing (data not shown). The mutation created a new HhaI restriction site.

\section{Expression of both a wild-type and a mutated RET} allele in TT cells

A fragment of the appropriate size (203 bp) resulted from RT-PCR of RNA from TT cells by using primers located in exons 10 and 11. The nucleotide sequence of RT-PCR product was confirmed by directly sequencing. The new HhaI restriction site produces the 106 and $97 \mathrm{bp}$ fragment in the mutant allele, but not in the wild-type allele. Restriction analysis of RT-PCR fragments from TT cells showed digested and undigested fragments, and these results imply expression of both the wildtype and the mutated allele of RET proto-oncogene in TT cells (Fig. 3 ).

\section{Discussion}

There have been a few reports describing genetic changes in sporadic MTCs. One is the loss of heterozygosity $(\mathrm{LOH})$ on chromosomes $1 \mathrm{p}$ and /or $22 \mathrm{q}$ in a few MTCs, and no consistent $\mathrm{LOH}$ in any chromosome 10 probes tested [16-19]. Another is the low mutation frequency of the ras or $p 53$ genes $[16,20]$. We also reported that $\mathrm{LOH}$ on informative loci, or mutations of the ras, p53 or gsp genes in sporadic MTCs were undetectable [14, 21-23]. Thus, the precise gene(s) responsible for sporadic MTC and the mechanism relating to its structural alterations to development of the tumor have yet to be defined.

Germline mutations of the RET proto-oncogene have been described in patients with MEN 2A, FMTC and MEN 2B [4-10]. The RET proto-oncogene encodes a protein structurally related to transmembrane receptors with cytoplasmic tyrosine-kinase domains, but its putative ligand has not yet been identified [24, 25]. Direct evidence for the involvement of the RET proto-oncogene in human tumors has been obtained in human thyroid papillary carcinomas [26]. Recently, Santoro et al. reported that mutations of the RET protooncogene play a critical role in tumor formation as a consequence of the activation of the RET protooncogene kinase [27]. Substitution from cysteine to other amino acids in MEN 2A is considered to disrupt normal disulfide bonds, and leads to activated homodimers of RET protein. And MEN 2B mutation, substitution from methionine to threo- 
nine at codon 918, alters the substrate specificity of $R E T$ protein without dimerization.

We confirmed that tumor DNAs of MTCs and pheochromocytomas from 2 patients with MEN 2A and one with FMTC had mutations of cysteine residues in the extracellular cysteine-rich region. In these patients, these mutations were also found in their leukocyte DNA, indicating germline mutations of the RET proto-oncogene. In the genetic forms of MTC, a germline mutation of the RET proto-oncogene may result in the initial hyperproliferation of C-cells. Subsequent genetic steps, possibly at other chromosome loci, presumably result in selected clonal transformation.

With respect to sporadic MTCs, Donis-Keller et al. [5, 9] have found only one mutation in 16 MTCs by analysing exons 10 and 11 of the RET protooncogene. This caused a 6 bp deletion that removed the cysteine residue at codon 630 , but clinical data from the patient with this deletion were not reported. Although Eng et al. [10] detected a codon 918 mutation (ATG to ACG) in 5 of 13 sporadic MTCs, no mutations in exon 10 or 11 were detected in 13 sporadic MTCs. Blaugrund et al. also identified codon 918 mutations in 6 of 15 clinically sporadic cases of MTC [28]. Mutations of the RET proto-oncogene in sporadic MTCs were mainly detected at codon 918 rather than within the cysteine-rich region. But in this study, three MTCs and TT cells had mutations at cysteine residue in the cysteine-rich region. The TT cell line was established from a 77-year-old patient with a sporadic MTC $[18,29]$. In TT cells, we detected a point mutation at codon 634 and expression of both the mutant allele and wild-type allele of the RET proto-oncogene by restriction analysis of RT-PCR products. These results were concordant with a recent report [27]. Our one sporadic MTC patient had a $6 \mathrm{bp}$ deletion, which resulted in the loss of a cysteine residue at codon 634, distinct from loss of that at codon 630 reported by Donis-Keller et al. [5, 9]. According to a study of 118 families with inherited MTC, mutations detected in patients with MEN 2A and FMTC were restricted to 5 cysteine residues (codons 609, 611, 618, 620 and 634), of which the most frequent events were at codon 634 [6]. Therefore, the somatic $6 \mathrm{bp}$ deletion including codon 634 and the mutation causing a substitution from cysteine to tyrosine at codon 634 in sporadic MTCs in patients 1 and 2 may play an important role in the tumorigenesis of sporadic MTCs.
A 6 bp deletion in patient 1 may be due to the accumulation of DNA damage or incompleteness of DNA repair accompanying aging, but the relation between molecular events and the aging process is controversial. As his MTC lesion was asymptomatic and had no regional lymph node metastases, it might be a slowly progressive type.

Several investigators have screened for mutations in exon 10 and 11 of the RET gene in sporadic MTCs and failed to find somatic events in these regions $[5,10,28,30]$. Our two patients do have somatic mutations within the cysteine-rich region, but the frequency could not be discussed because of the limited number of our patients. Although difference in the frequency of mutations may be attributed to racial difference, a large scale study should be conducted.

We found a conversion of the cysteine residue to serine at codon 618 in a case of clinically apparent sporadic MTC (patient 3). Since this patient was diagnosed as having sporadic type due to the apparent absence of any family history of MTC, signs of associated endocrine lesions or bilateral thyroid involvement of MTC, she was not screened until diagnosis. Analysis of the DNAs from her leukocytes revealed the same mutation as well as the MTC. These results indicated that the patient in fact had hereditary MTC. Because the genetic change was probably transmitted to her offspring, DNA analysis for the detection of the mutation should be carried out to identify subjects at risk, but unfortunately we could not obtain their consent. Olson et al. have reported that information about family history, clinical presentation, and histopathologic examination are not sufficient to exclude hereditary forms of MTC [31]. The case of a germline mutation at codon 618 in a clinically sporadic MTC patient was reported by Blaugrund et al. [28]. In future, genetic markers such as mutations of the RET proto-oncogene should be used as an aid in distinguishing sporadic from hereditary MTC.

\section{Acknowledgments}

We thank Drs. Masaru Tsuyuguchi, Isao Morimoto, Sumiya Eto, Ryoyu Takeda, Ryuichiro Soma, Kozo Hashimoto, Tsuneo Ogawa, Haruo Sumitani, Kunio Ogasawara, Ryuichi Yamasaki, Hideo Takahashi, Kazuto Kameyama, Keiko Miya, Hidetaka 
Horie, Toshihiko Inoue, and Emiko Hosoi for providing tumors. We thank Drs. Toshiaki Sano, Hisajiro Kumagai, and Hiroshi Morizumi for pathological diagnosis. We thank Miss Chisato Tanaka and Miss Maki Moritani for technical assistance. We are grateful to Professor Mitsuo Itakura for continuous support. This work was supported in part by a Grant-in-Aid for Scientific Research from the Ministry of Education, Science and Culture of Japan to S. S., and by a grant from Otsuka Pharmaceutical Factory, Inc., for Otsuka Department of Clinical and Molecular Nutrition, School of Medicine, The University of Tokushima.

\section{References}

1. DeLellis RA (1993) The pathology of medullary thyroid carcinoma and its precursors. Monogr Pathol (United States) 35: 72-102.

2. Gardner E, Papi L, Easton DF, Cummings T, Jackson CE, Kaplan M, Love DR, Mole SE, Moore JK, Mulligan LM, Norum RA, Ponder MA, Reichlin S, Stall G, Telenius H, Telenius-Berg M, Tunnacliffe A, Ponder BAJ (1993) Genetic linkage studies map the multiple endocrine neoplasia type 2 loci to a small interval on chromosome 10q11.2. Hum Mol Genet 2: 241-246.

3. Mole SE, Mulligan LM, Healey CS, Ponder BAJ, Tunnacliffe A (1993) Localization of the gene for multiple endocrine neoplasia type $2 \mathrm{~A}$ to a $480 \mathrm{~kb}$ region in chromosome band 10q11.2. Hum Mol Genet 2: 247-252.

4. Mulligan LM, Kwok JBJ, Healey CS, Elsdon MJ, Eng C, Gardner E, Love DR, Mole SE, Moore JK, Papi L, Ponder MA, Telenius H, Tunnacliffe A, Ponder BAJ (1993) Germ-line mutations of the RET proto-oncogene in multiple endocrine neoplasia type 2A. Nature 363: 458-460.

5. Donis-Keller H, Dou S, Chi D, Carlson KM, Toshima K, Lairmore TC, Howe JR, Moley JF, Goodfellow P, Wells SA Jr (1993) Mutations in the RET protooncogene are associated with MEN 2A and FMTC. Hum Mol Genet 2: 851-856.

6. Mulligan LM, Eng C, Healey CS, Clayton D, Kwok JBJ, Gardner E, Ponder MA, Frilling A, Jackson CE, Lehnert H, Neumann HPH, Thibodeau SN, Ponder BAJ (1993) Specific mutations of the RET protooncogene are related to disease phenotype in MEN 2A and FMTC. Nature Genet 6: 70-74.

7. Tsai M-S, Ledger GA, Khosla S, Gharib H, Thibodeau SN (1994) Identification of multiple endocrine neoplasia, type 2 gene carriers using linkage analysis and analysis of the ret proto-oncogene. $J$ Clin Endocrinol Metab 78: 1261-1264.

8. Hofstra RMW, Landsvater RM, Ceccherini I, Stulp RP, Stelwagen T, Luo Y, Pasini B, Hoppener JWM, van Amstel HKP, Romeo G, Lips CJM, Buys CHC (1994) A mutation in the RET proto-oncogene associated with multiple endocrine neoplasia type $2 \mathrm{~B}$ and sporadic medullary thyroid carcinoma. Nature
367: 375-376.

9. Carlson KM, Dou S, Chi D, Scavarda N, Toshima $\mathrm{K}$, Jackson CE, Wells SA Jr, Goodfellow PJ, DonisKeller H (1994) Single missense mutation in the tyrosine kinase catalytic domain of the RET protooncogene is associated with multiple endocrine neoplasia type 2B. Proc Natl Acad Sci USA 91: 1579-1583.

10. Eng C, Smith DP, Mulligan LM, Nagai MA, Healey CS, Ponder MA, Gardner E, Scheumann GFW, Jackson CE, Tunnacliffe A, Ponder BAJ (1994) Point mutation within the tyrosine kinase domain of the $R E T$ proto-oncogene in multiple endocrine neoplasia type $2 \mathrm{~B}$ and related sporadic tumors. Hum Mol Genet 3: 237-241.

11. Santoro $M$, Rosati $R$, Grieco $M$, Berlingieri MT, D'Amato GL, de Franciscis V, Fusco A (1990) The ret proto-oncogene is consistently expressed in human pheochromocytomas and thyroid medullary carcinomas. Oncogene 5: 1595-1598.

12. Miya A, Yamamoto $M$, Morimoto $H$, Tanaka N, Shin E, Karakawa K, Toyoshima K, Ishizaka Y, Mori T, Takai S (1992) Expression of the ret protooncogene in human medullary thyroid carcinomas and pheochromocytomas of MEN 2A. Henry Ford Hosp Med J 40: 215-219.

13. Yoshimoto K, Iizuka M, Iwahana $H$, Yamasaki $R$, Saito H, Saito S, Sekiya T (1989) Loss of the same alleles of HRAS1 and D11S151 in two independent pancreatic cancers from a patient with multiple endocrine neoplasia type 1. Cancer Res 49: 2716-2721.

14. Yoshimoto K, Iwahana H, Fukuda A, Sano T, Saito S, Itakura M (1992) Role of p53 mutations in endocrine tumorigenesis: Mutation detection by polymerase chain reaction-single strand conformation polymorphism. Cancer Res 52: 5061-5064.

15. Chomczynski P, Sacchi N (1987) Single-step method of RNA isolation by acid guanidinium thiocyanatephenol-chloroform extraction. Anal Biochem 162: 156-159.

16. Okazaki M, Miya A, Tanaka N, Miki T, Yamamoto M, Motomura K, Miyauchi A, Mori T, Takai S (1989) Allele loss on chromosome 10 and point mutation of ras oncogenes are infrequent in tumors of MEN 
2A. Henry Ford Hosp Med J 37: 112-115.

17. Yang K-P, Nguyen CV, Castillo SG, Samaan NA (1990) Deletion mapping on the distal third region of chromosome 1p in multiple endocrine neoplasia type IIA. Anticancer Res 10: 527-534

18. Nelkin BD, Nakamura $Y$, White RW, de Bustros AC, Herman J, Wells SA Jr, Baylin SB (1989) Low incidence of loss of chromosome 10 in sporadic and hereditary human medullary thyroid carcinoma. Cancer Res 49: 4114-4119.

19. Khosla S, Patel VM, Hay ID, Schaid DJ, Grant CS, van Heerden JA, Thibodeau SN (1991) Loss of heterozygosity suggests multiple genetic alterations in pheochromocytomas and medullary thyroid carcinomas. J Clin Invest 87: 1691-1699.

20. Yana I, Nakamura T, Shin E, Karakawa K, Kurahashi H, Kurita Y, Kobayashi T, Mori T, Nishisho I, Takai S (1992) Inactivation of the p53 gene is not required for tumorigenesis of medullary thyroid carcinoma or pheochromocytoma. Jpn J Cancer Res 83: 113-1116.

21. Kubo K, Yoshimoto K, Yokogoshi Y, Tsuyuguchi M, Saito S (1991) Loss of heterozygosity on chromosome $1 \mathrm{p}$ in thyroid adenoma and medullary carcinoma, but not in papillary carcinoma. Jpn J Cancer Res 82: 1097-1103.

22. Yoshimoto $K$, Iwahana $H$, Fukuda A, Sano $T$, Katsuragi K, Kinoshita M, Saito S, Itakura M (1992) ras mutations in endocrine tumors: Mutation detection by polymerase chain reaction-single strand conformation polymorphism. Jpn J Cancer Res 83: 1057-1062.

23. Yoshimoto K, Iwahana H, Fukuda A, Sano T, Itakura M (1993) Rare mutations of the Gs alpha subunit gene in human endocrine tumors: Mutation detection by polymerase chain reaction-primer-introduced restriction analysis. Cancer 72: 1386-1393.

24. Takahashi M, Buma $Y$, Iwamoto T, Inaguma $Y$, Ikeda H, Hiai H (1988) Cloning and expression of the ret proto-oncogene encoding a tyrosine kinase with two potential transmembrane domains. Oncogene 3: 571-578.

25. Takahashi M, Buma Y, Hiai H (1989) Isolation of ret proto-oncogene cDNA with an amino-terminal signal sequence. Oncogene 4: 805-806.

26. Grieco M, Santoro M, Berlingieri MT, Melillo RM, Donghi R, Bongarzone I, Pierotti MA, Della Porta G, Fusco A, Vecchio G (1990) PTC is a novel rearranged form of the ret proto-oncogene and is frequently detected in vivo in human thyroid papillary carcinoma. Cell 60: 557-563.

27. Santoro M, Carlomagno F, Romano A, Bottaro DP, Dathan NA, Grieco M, Fusco A, Vecchio G, Matoskova B, Kraus MH, Di Fiore PP (1995) Activation of RET as a dominant transforming gene by germline mutations of MEN 2A and MEN 2B. Science 267 : 381-383

28. Blaugrund JE, Johns MM Jr, Eby YJ, Ball DW, Baylin SB, Hruban RH, Sidransky D (1994) RET protooncogene mutations in inherited and sporadic medullary thyroid cancer. Hum Mol Genet 3: 18951897.

29. Leong SS, Horoszewicz JS, Shimaoka K, Friedman M, Kawinski E, Song MJ, Ziegel R, Chu TM, Baylin S, Mirand EA (1981) A new cell line for study of human medullary thyroid carcinoma. In: Andreoli M, Monaco F, Robbins J (eds) Advances in Thyroid Neoplasia. Field Educational Italia, Rome: 95-108.

30. Quadro L, Panariello L, Salvatore D, Carlomagno F, Del Prete M, Nunziata V, Colantuoni V, Di Giovanni G, Brandi ML, Mannelli M, Gheri R, Verga U, Libroia A, Berger N, Fusco A, Grieco M, Santoro $M$ (1994) Frequent RET protooncogene mutations in multiple endocrine neoplasia type $2 \mathrm{~A}$. J Clin Endocrinol Metab 79: 590-594.

31. Olson JE, Hughes J, Alpern HD (1992) Family members of patients with sporadic medullary thyroid carcinoma must be screened for hereditary disease. Surgery 112: 1074-1079. 